\title{
Gravimetric, electrochemical and surface study on the good's buffer ionic liquid as corrosion inhibitor for carbon steel in acidic medium
}

\author{
R. Nanthini ${ }^{1 *}$, M.I. Mutalib ${ }^{1}$, and K.A Kurnia ${ }^{1}$ \\ ${ }^{1}$ Department of Chemical Engineering, Universiti Teknologi PETRONAS \\ 32610 Bandar Seri Iskandar, Perak, Malaysia, \\ Phone: +60165394695; Fax: +6053656176 \\ *Email: nanthiniraman1993@gmail.com.my
}

\begin{abstract}
This corrosion study assessed the inhibition performance of carbon steel in $1 \mathrm{M}$ of hydrochloric acid $(\mathrm{HCl})$ using Good's buffer ionic liquids (GBIL) namely 1-Butyl-3methylimidazolium 2-(N-Morpholino) propane, [BMIM][MOPS] using electrochemical impedance, potentiodynamic polarization, and weight loss (gravimetric) measurements. GBIL are synthesized by the combination of Good's buffer as anion and various organic bases as the cation. The gravimetric measurements exhibit higher reduction in weight for carbon steel exposed to the acidic environment in the absence of corrosion inhibitor (CI) as compared to carbon steel immersed in the presence of inhibitor molecule. Potentiodynamic polarization study indicates that the synthesized inhibitor acted as a mixed type inhibitor. The inhibition efficiency increases with increase in the concentration of [BMIM][MOPS]. Corrosion protection efficiency ranging from $88 \%$ to $90 \%$ was featured at $800 \mathrm{ppm}$ of CI in the $\mathrm{HCl}$ medium. The adsorption of [BMIM][MOPS] on the carbon steel surface was described by the Langmuir's adsorption isotherm. The scanning electron micrographs inspected the morphology of the carbon steel surface exposed to the solution without and with the presence of inhibitor. The result showed that compound effectively suppressed corrosion by the appearance of an improved surface structure of carbon steel with increasing concentration of [BMIM][MOPS].
\end{abstract}

Keywords: Corrosion; ionic liquids; langmuir; tafel polarization; buffer.

\section{INTRODUCTION}

Carbon steel is prominently used as construction materials in diverse industrial sectors in particular heat exchangers, flow lines and transmission pipelines. Its extensive use attributed due to its outstanding mechanical properties, readily available and inexpensive cost. Acidic intermediates are widely employed in majority core processes in industry, for instances acid descaling, industrial acid cleaning and oil well acidizing [1]. The usage of the corrosive medium often subject carbon steel susceptible to degradation due to corrosion attack. Corrosion process is known as a type of surface reaction whereby metal is corroded by oxidation which releases electron and simultaneously free electrons are accepted at the cathodic part of a metal. In line with surface chemistry, the physical boundaries at which 
metal corrosion takes place could be altered by the potential occupancy of new adsorbed molecules. These can be curbed by introducing compounds known as inhibitors. Corrosion inhibitors are introduced into a system internally to minimize the corrosive attack on the metallic materials upon a small quantity of addition. An effective inhibitor capable of reducing the water and corrosive species shift to and from the metal surface by means of adsorption [2].

Organic inhibitors are widely appreciated due to the presence of active functional groups that contributes for the adsorption on the metal surface. The enhancement of inhibition efficiency depends on the presence of unsaturated bonds and electronegative atoms, such as oxygen, nitrogen, and sulfur in the long chain compounds [3] of organic inhibitors. In the past years, corrosion inhibitors from the Ionic liquids (ILs) groups have been studied as potential candidate to supress corrosion of different metallic substrates due to their high activity in acidic solution [4]. ILs are identified as organic salts with comparatively low vapor pressure with a melting point beneath $100^{\circ} \mathrm{C}$. Thus, known as a good green solvent substitute to those volatile organic solvents [5]. ILs are known for its tuneable property whereby the choice of cation and anion can be synthesized accordingly which offers promising features such as being thermally stable up to $300-400^{\circ} \mathrm{C}$. Besides, the availability of wide electrochemical window, up to $7 \mathrm{~V}$ permits ILs to be employed as corrosion inhibitor due to its ability to conduct electricity [6]. In particular, imidazoliumbased ILs are commonly chosen due to their ability to perform well in acidic mediums [7]. The presence of the aromatic group in the imidazolium molecules and ability to protonate in the acidic medium promotes the inhibition action. The structure elucidation of Imidazolium bases, exhibits the $-\mathrm{C}=\mathrm{N}-$ group which promotes for a big $\pi$ bond establishment [8]. The lone pair contribution in the imidazolium bases enters unoccupied orbitals of iron. Moreover, a feedback bond can be initiated as the $\pi$ orbital able to accept the electrons of $d$ orbitals of the transition metal, iron resulting in improved inhibition efficiency [9]. Even though imidazolium-based ILs are considered as an excellent cation source of corrosion inhibitors, the current corrosion inhibitor of ILs have limited anion to work as corrosion inhibitors. Most of the readily available compounds derived from Imidazole are synthesized with fluorinated anions, especially $\mathrm{Cl}^{-}, \mathrm{Br}^{-} \mathrm{I}^{-}$and bis-(trifluoromethylsulfonyl) imide [ $\left.\mathrm{NTf}_{2}\right]$ or tosylate anion. Several anions, such as tetrafluoroborate, $\left[\mathrm{BF}_{4}\right]^{-}$, and hexafluorophosphate, $\left[\mathrm{PF}_{6}\right]^{-}$, not suitable to function as corrosion inhibitor due to possible hydrolysis in the aqueous solution [10]. Recently, Olivares et al. have concluded that the presence of anion provides synergism effect combined with the cation part of a molecule to impede corrosion acidic medium [11].

This study introduces a new class of Good Buffer Ionic Liquid (GBIL) consisting of Imidazolium as cation and selected Good's buffer as anion. Good's buffer is named after Norman Good and co-workers [12]. Good's buffers are popularly used by biochemical and biological researchers because they are mostly water soluble and does not interfere with biological processes or biological membrane [13]. This characteristic provides the platform for safe use of buffer as GBIL in acidic medium. Most importantly, buffer offers wide adsorption sites with numerous electronegative atoms required as adsorption centers. Tricine, (N-(Tri(hydroxymethyl)methyl) glycine) for instance, from the buffer group, has been tested to control the erosion of zinc in neutral chloride solution [14]. The tricine buffer performed well as an effective green corrosion inhibitor for zinc to impede corrosion by the presence of 
$-\mathrm{OH}$ and $-\mathrm{NH}$ functional groups. This reveals that buffer available as a potential candidate for an anion.

To the knowledge of the author, the use of Good's buffer ionic liquids as a corrosion inhibitor in the acidic environment with carbon steel is yet to be revealed. Taking into account the chemical characterization of GBIL, in this work, the use of [BMIM][MOPS] as the corrosion inhibitor in acidic medium was evaluated using different electrochemical techniques and weight loss method. Thermodynamic parameters have been quantified and prudently discussed.

\section{METHODS AND MATERIALS}

\section{Material Preparation}

The experimental material for this study was steel API 5L X52 coupons with chemical composition of (wt\%): $0.08 \mathrm{C}, 1.06 \mathrm{Mn}, 0.26 \mathrm{Si}, 0.019 \mathrm{P}, 0.003 \mathrm{~S}, 0.0039 \mathrm{Al}, 0.041 \mathrm{Nb}$, $0.018 \mathrm{Cs}, 0.02 \mathrm{Cr}, 0.019 \mathrm{Ni}, 0.054 \mathrm{~V}, 0.003 \mathrm{Ti}, 0.0002 \mathrm{Ca}, 0.0003 \mathrm{~B}$ and the balance being Fe. Prior to all measurements, test specimens surface was polished to a mirror finish using grit emery paper of different grades (800, 1200 and 2400). The studied buffer, MOPS purchased from Sigma Aldrich $(98 \% \mathrm{wt}$ ). Dilution of analytical grade $37 \% \mathrm{HCl}$ was prepared by double distilled water for the attack solution $(1 \mathrm{M} \mathrm{HCl})$.

\section{General Procedure for Ionic Liquid Synthesis}

Equimolar of [BMIM]Cl $(0.05 \mathrm{~mol})$ and potassium hydroxide $(0.05 \mathrm{~mol})$ were taken in a double neck round bottomed flask with ethanol as eluent. The mixture is then stirred in a single round-bottomed flask equipped with reflux condenser, magnetic stirrer, and thermostat for 6 hours. The mixing temperature $T_{m i x}$ is set at $25 \pm 1{ }^{\circ} \mathrm{C}$ and monitored carefully. At the end of six hours, precipitation of potassium chloride was observed. The salt layer was separated by vacuum filtration and eliminated. The step is repeated three times to ensure high purity of end material. The filtrate was then filtered through a funnel with sintered glass to remove the residual halide salt. Finally, equimolar of buffer Mops was mixed with filtrate solution and concentrated by rotary evaporation to afford colourless viscous liquid with a yield of about $98 \%$. IL of [BMIM][MOPS] was further dried in vacuum oven for 8 hours at $80{ }^{\circ} \mathrm{C}$. The water content of the synthesized IL was tested against Karl Fisher to allow a tolerance of $1000 \mathrm{ppm}$ water content. The molecular configuration of [BMIM][MOPS] is depicted in Figure 1. Chemical shifts of the prepared ILs are expressed as in $\delta(\mathrm{ppm})$ and obtained with Bruker AMX 300 equipment.

[Bmim][MOPS] : 1H NMR (300 MHz, DMSO) ; $\delta$ [Bmim] , 0.93 (3H,d, C1's H), $1.08(2 \mathrm{H}$, m, C2's H), 1.80 (2H, m, C3's H), 3.91 (3H, t, C8's H), 4.22 (2H, t, C4's H), 7.86 (1H, s, C6's H) , 7.79 ( 1H,s, C7's H) , 9.32 ( 1H, s, C5's H); [MOPS], 2.43 (4H, t, C4C6's H), 2.51 (2H, t, C3's H), 2.62 (2H, t, C2's H), 2.68 (2H,t,C1's H) , 3.64 (4H, t, C3C5's H). 

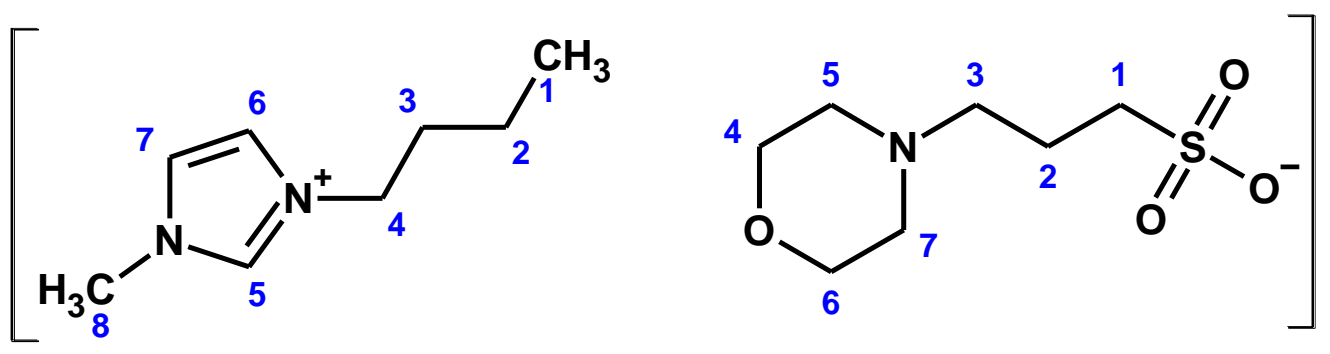

Figure 1. Molecular structure of [BMIM][MOPS].

\section{Weight Loss Measurement}

Weight loss experiment was carried out as per the ASTM G1-03 techniques. The initial weight of test specimens with a dimension of $1.0 \mathrm{~cm} \times 1.0 \mathrm{~cm} \times 0.05 \mathrm{~cm}$ were recorded prior to immersion in the corrosive medium. Steel specimens were immersed in a $100-\mathrm{mL}$ corrosive solution for a period of 24 hours at $25 \pm 1{ }^{\circ} \mathrm{C}$ in the absence and presence of the CI. The concentration of inhibitor varied between 200 to $800 \mathrm{ppm}$. The soaked coupons removed from the test solution, washed in double distilled water, dried under nitrogen and then reweighted [15]. This test was repeated in triplicate to obtain an average value of weight loss.

\section{Electrochemical Analysis Measurement}

Electrochemical tests were performed by General Purpose Electrochemical System (GPES) software provided by AUTOLAB. A three-electrode cell consisting of test coupons as working electrode, a platinum sheet with a $1 \mathrm{~cm}^{2}$ surface area (auxiliary electrode) electrode and standard calomel electrode (reference electrode) were used. The working electrode is immersed in the test solution for duration of 30 minutes to attain stabilization at the open circuit potential $\left(\mathrm{E}_{\mathrm{ocp}}\right)$. EIS measurement was performed in the frequency range of $100 \mathrm{KHz}$ to $0.1 \mathrm{~Hz}$ with signal amplitude perturbation of $10 \mathrm{mV}$ using alternating current (AC). Potentiodynamic polarization was carried out in the potential range of $\pm 300 \mathrm{mV}$ at a scan rate of $10 \mathrm{mV} /$ minute. All electrochemical tests have been performed under unstirred conditions. Obtained potentials were documented with respect to SCE [16]. Each electrochemical measurement was reproduced three times under the same test environment and means values of, corrosion current density and charge transfer resistance computed to ensure reliability.

\section{Microstructure Analysis}

The surface morphology of the test specimen before and after immersed in the corrosive medium in the absence and presence of inhibitor [BMIM][MOPS] was evaluated using scanning electron microscopy (SEM). The SEM images were taken using equipment model of Zeiss Supra 55 VP at magnification scale of 1000x. 


\section{RESULTS AND DISCUSSION}

\section{Weight Loss Measurements}

The weight loss of the test specimens in $1.0 \mathrm{M} \mathrm{HCl}$ with the absence and presence of varying concentrations of [BMIM][MOPS] of 200,400, 600, and 800 ppm were obtained after 24hour immersion at $25 \pm 1{ }^{\circ} \mathrm{C}$. Gravimetric measurement carried out for such period of time to ensure equilibrium is attained in the system and impart a measurable corrosion rate. The weight loss result obtained is summarized in Table 1 . The corrosion rate, $C R$ is calculated by Equation (1):

$$
C R=\frac{K \times W}{A \times T \times D}
$$

whereby $K$ is a constant $\left(1.00 \times 10^{4} \times D\right), W$ is the mass loss $(m g), T$ is the time of exposure in hours, $A$ is the area $\left(\mathrm{cm}^{2}\right)$ and $D$ is the density of the carbon steel. The correlation between the surface coverage, $\theta$ and Inhibition Efficiency, (IE \%) are provided in Equation (2) :

$$
\theta=\frac{I E \%}{100}
$$

Table 1. Corrosion parameter from weight loss measurement for carbon steel in the presence and absence of various concentrations of [BMIM][MOPS] at $25{ }^{\circ} \mathrm{C}$.

\begin{tabular}{cccc}
\hline $\begin{array}{c}\text { Concentration } \\
(\mathrm{ppm})\end{array}$ & $\begin{array}{c}\mathrm{CR} \\
\left(\mathrm{mg} \mathrm{cm}^{-2} \mathrm{~h}^{-1}\right)\end{array}$ & $\begin{array}{c}\mathrm{IE} \\
(\%)\end{array}$ & $\theta$ \\
\hline 1 M HCl Blank & 4.80 & - & - \\
\hline$[$ BMIM][MOPS] & & & \\
200 & 1.58 & 67 & 0.67 \\
400 & 1.32 & 73 & 0.73 \\
600 & 0.73 & 83 & 0.83 \\
800 & 0.53 & 88 & 0.88 \\
\hline
\end{tabular}

Table 1 depicts the corrosion rate and inhibition efficiency in the absence and presence of inhibitor, [BMIM][MOPS]. It can be deduced that the corrosion rate of carbon steel is inversely proportional to the inhibition efficiency. The result is more pronounced as the concentration of the inhibitor increases respectively. As presented in Table 1, [BMIM][MOPS] provides highest inhibition of $88 \%$ at $800 \mathrm{ppm}(2.4 \mathrm{mM})$. Based on previous literature, the inhibition efficiency of [BMIM]Cl at $5 \mathrm{mM}$ is given at $81 \%$ [17]. This is due to the fact that, the size of anion [MOPS] ${ }^{-}$is larger than anion $\mathrm{Cl}^{-}$. Thus, lesser concentration of [BMIM][MOPS] needed to achieve higher inhibition and larger surface coverage than $[\mathrm{BMIM}] \mathrm{Cl}$. The large surface coverage, delays the hydrogen evolution and metal dissolution process [18]. The studied system is recorded at $800 \mathrm{ppm}$ (optimum) as further increase of [BMIM][TOS] concentration exhibit only a small significant improvement in the inhibiton efficiency. This might be attributed by a monolayer saturation of the adsorbed inhibitor on the active sites of metal surface [10]. 


\section{Electrochemical Impedance Spectroscopy (EIS)}

The test specimens' interface changes with respect to the presence and absence of CI can be evaluated by means of electrochemical impedance measurements.

The Nyquist plot for carbon steel in $1 \mathrm{M} \mathrm{HCl}$ solution with various concentrations of inhibitor, [BMIM][MOPS] presented in Figure 2. The impedance spectra consist of a large capacitive loop at high frequency denoted by the semi-circular shape of the Nyquist plot. This typical representation might indicate the charge transfer of the corrosion process as well the double layer behaviour. It is obvious that the impedance modulus of the unhibited system is much smaller than that compared in the inhibited solution. This may due to the presence of $\mathrm{Cl}^{-}$ion in the attack solution, accelerating the corrosion process [19]. Nevertheless, with the addition of corrosion inhibitor, the diameter of the capacitive loop gradually increased. The presence of [BMIM][MOPS] allow for such behaviour as the inhibitor reduces the corrosion attack by obstructing the active sites available for corrosion attack [20].

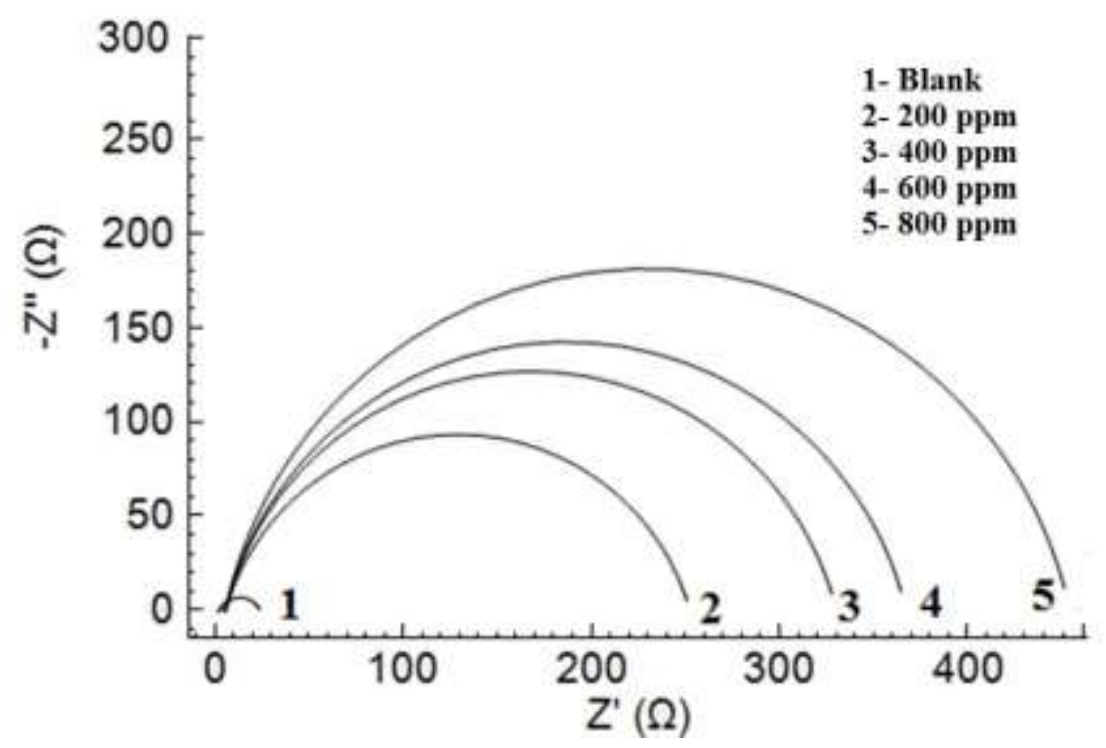

Figure 2. Nyquist plot for carbon steel in the presence and absence of various concentrations of $[\mathrm{BMIM}][\mathrm{MOPS}]$ at $25^{\circ} \mathrm{C}$.

A Randles circuit is used to interpret the impedance spectra of EIS. In this electrochemical circuit, $R_{s}$ is the solution resistance, $C_{d l}$ is the double layer capacitance that characterizes the separation of metal/electrolyte interface and $R_{t}$, given as charge transfer resistance. Charge transfer resistance is crucial as it reflects the electron transfer across the anodic to cathodic site in a corrosion system [21]. The inhibition efficiency (IE \%) is calculated by Equation (3)

$$
I E(\%)=\frac{R_{t}-R_{t}^{0}}{R_{t}}
$$

where $R_{t}^{0}$ and $R_{t}$ are charger transfer resistances in the absence and presence of inhibitors respectively. 


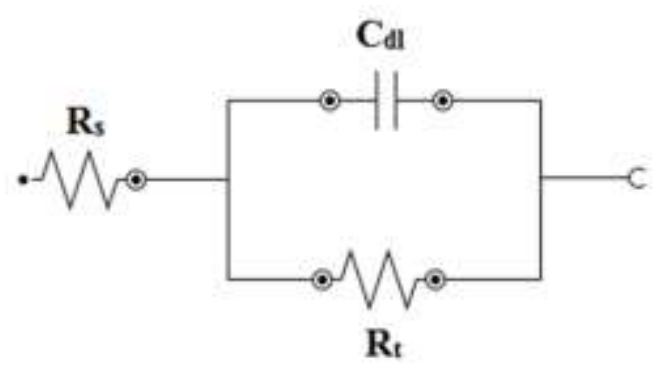

Figure 3. Randles equivalent circuit.

Table 2 presents the electrochemical parameters of $R_{t}, C_{d l}$ and inhibition efficiency (IE \%). The charge transfer resistance values changes with the addition of CI. It appears that the presence of CI increases the $R_{t}$ value that leads to the rise of inhibition efficiency. More molecules are adsorbed on the metal surface, allowing a thicker adsorption film formation. Thus, more difficult the charge transfer process becomes [22]. However, a decrease in double layer capacitance, $C_{d l}$ from 184 to $48 \mu F \cdot \mathrm{cm}^{-2}$ is observed. When there is a reduction trend in $C_{d l}$ with increasing [BMIM] [MOPS] concentrations in the solution can then indicate the formation of adsorbed inhibitor layer on the steel surface. [BMIM][MOPS] most likely blocks the steel surface from corrosive attack as there is a gradual replacement of water molecules by the inhibitor on the steel surface [23]. This could reduce the metal matrix and corrosive media contact and prevent further attack.

It is apparent that, with the addition of [BMIM] [MOPS], only a single peak is observed (one time constant) in Bode modulus as illustrated in Figure 4. This indicates the corrosion of carbon steel in $1 \mathrm{M} \mathrm{HCl}$ is primarily dominated by a charge transfer process [24]. As according to the appearance of Bode-phase plot in Figure 5, the phase angle increases with the addition of [BMIM][MOPS]. This suggests that the surface coverage on carbon steel is pronounced when more inhibitor molecules are adsorbed on the metal surface [25].

Table 2. EIS parameters and corresponding inhibition efficiency for carbon steel in the presence and absence of various concentrations of [BMIM][MOPS] at $25^{\circ} \mathrm{C}$.

\begin{tabular}{cccc}
\hline Concentration $(\mathrm{ppm})$ & $R_{t}\left(\Omega \cdot \mathrm{cm}^{2}\right)$ & $C_{d l}\left(\mu F \cdot \mathrm{cm}^{-2}\right)$ & $\mathrm{IE}(\%)$ \\
\hline 1 M HCl Blank & 45 & 375 & - \\
\hline [BMIM][MOPS] & & & \\
200 & 245 & 184 & 82 \\
400 & 319 & 107 & 86 \\
600 & 388 & 78 & 88 \\
800 & 450 & 48 & 90 \\
\hline
\end{tabular}




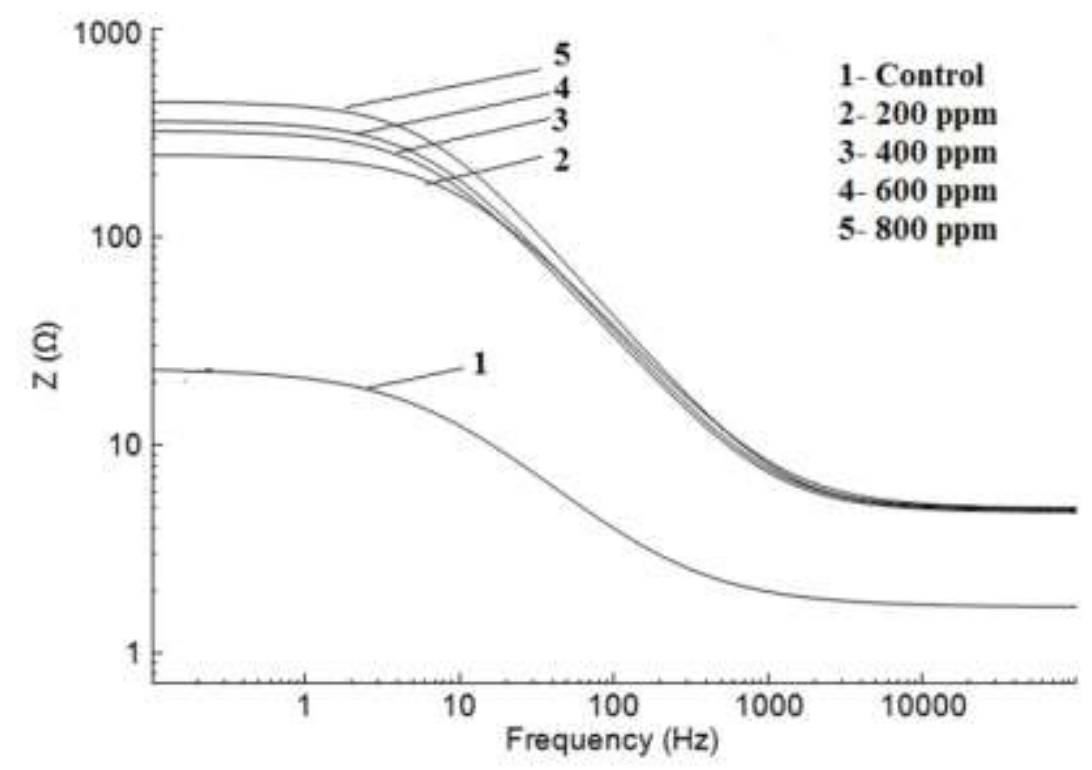

Figure 4: Bode-magnitude plot for carbon steel in the presence and absence of various concentrations of $[\mathrm{BMIM}][\mathrm{MOPS}]$ at $25^{\circ} \mathrm{C}$.

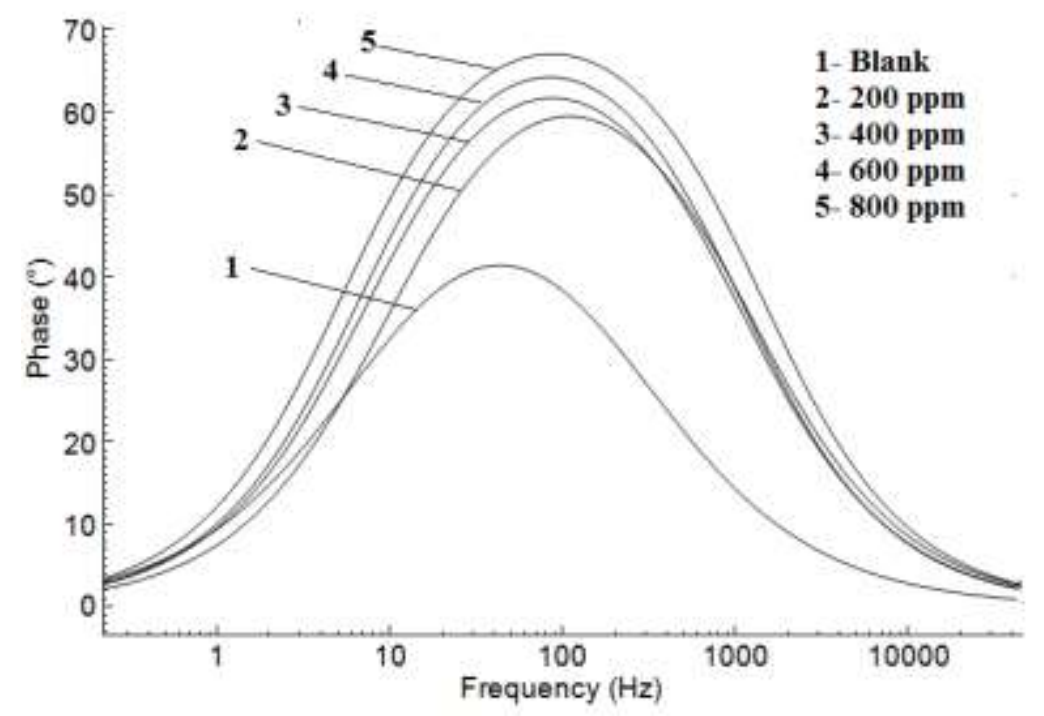

Figure 5. Bode-phase plot for carbon steel in the presence and absence of various concentrations of $[\mathrm{BMIM}][\mathrm{MOPS}]$ at $25^{\circ} \mathrm{C}$.

\section{Tafel Polarization Measurement}

Figure. 6 represents the polarization curves for [BMIM][MOPS] at $25^{\circ} \mathrm{C}$. The corrosion potential $\left(E_{\text {corr }}\right)$ and corrosion current density $\left(I_{\text {corr }}\right)$ are obtained by linear extrapolation of Tafel segments of the cathodic and anodic lines back to their intersection [26]. These data alongside IE\% are listed in Table 3 respectively. The IE \% is calculated from the value of corrosion current density, by Equation. (4) as follows: 


$$
\operatorname{IE}(\%)=\frac{I_{\text {corr }}^{0}-I_{\text {corr }}}{I_{\text {corr }}^{0}}
$$

where $I_{\text {corr }}^{0}$ and $I_{\text {corr }}$ are the corrosion current densities in the absence and presence of inhibitors respectively.

The data in Table 3 and Figure 6 reveals that, with the addition of [BMIM][MOPS] to the acidic medium, the value of $I_{\text {corr }}$ reduces significantly whereas, the value of $E_{\text {corr }}$ shifts towards a negative direction. It can be deduced that the addition of [BMIM][MOPS] inhibits both anodic dissolution of iron and hinders cathodic hydrogen evolution reaction. The inhibition effect was more pronounced on increasing [BMIM][MOPS] concentrations. The largest displacement of the $E_{\text {corr }}$ value observed at $46 \mathrm{mV}$ cathodically, for test specimen immersed in $\mathrm{HCl}$ solution with $800 \mathrm{ppm}$ [BMIM][MOPS] as compared to the uninhibited solution. Simultaneously, it worth noting that the shift of $E_{\text {corr }}$ upon the addition of inhibitor is $\geq 85 \mathrm{mV}$ with respect to the $E_{\text {corr }}$ of blank solution [27], the inhibitor can be classifies as cathodic or anodic type and if the shift is $\leq 85 \mathrm{mV}$, then the inhibitor may be regarded as a mixed-type [28]. Thus, from the obtained result, [BMIM][MOPS] suggested as a mixed-type inhibitor. The data measured from potentiodynamic polarization are consistent with the result obtained from gravimetric and EIS evaluation

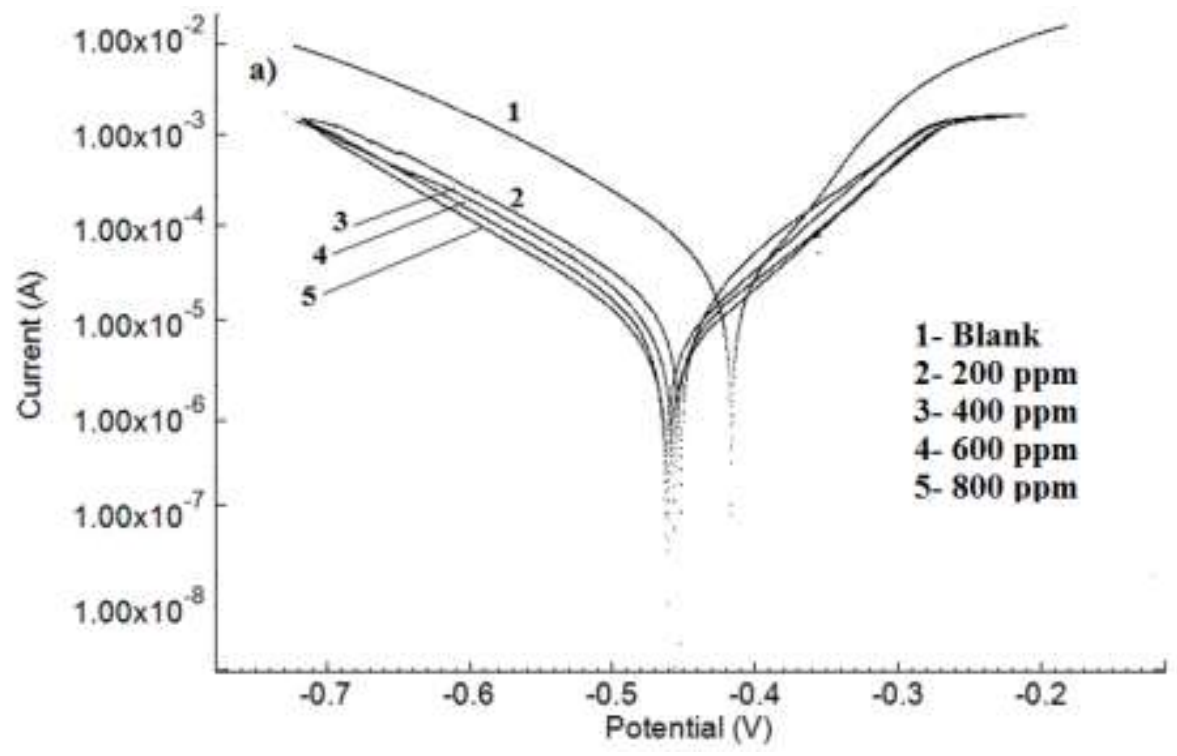

Figure 6. Polarization curve for carbon steel in the presence and absence of various concentrations of [BMIM] [MOPS] at $25^{\circ} \mathrm{C}$. 
Table-3. Polarization curves parameters and corresponding inhibition efficiency for carbon steel in the presence and absence of various concentrations of [BMIM][MOPS] at $25^{\circ} \mathrm{C}$.

\begin{tabular}{cccc}
\hline $\begin{array}{c}\text { Concentration } \\
(\mathrm{ppm})\end{array}$ & $\begin{array}{c}I_{\text {corr }} \\
\left(\mu \mathrm{A} \mathrm{cm}^{-2}\right)\end{array}$ & $\begin{array}{c}-E_{\text {corr }} \\
(\mathrm{mV})\end{array}$ & IE $(\%)$ \\
\hline 1 M HCl Blank & 546 & 417 & - \\
\hline [BMIM][MOPS] & & & \\
200 & 111 & 438 & 80 \\
400 & 95 & 441 & 83 \\
600 & 63 & 457 & 88 \\
800 & 52 & 463 & 90 \\
\hline
\end{tabular}

\section{Adsorption Isotherm}

Through adsorption isotherm equations, the degree of surface coverage values, $\theta$ (IE/100) and its function with concentration of inhibitors can be evaluated [29]. The best correlations between the data acquired from three different methods with several adsorption isotherms have been assessed. Langmuir's isotherm is found to fit well with the experimental data as shown in Figure 7. It is worth mentioning that the coefficients, $R^{2}$ of linear regression is approximate to unity $\left(R^{2}>0.99\right)$, indicating that the corrosion inhibitor obeys Langmuir isotherm [30]. The Langmuir isotherm is represented by Equation.5 as follows:

$$
\frac{C}{\theta}=\frac{1}{K_{a d s}}+C
$$

where $C$ corresponds to the concentration of inhibitor and $K_{a d s}$ is the equilibrium constant. The value of $K_{a d s}$ was calculated from the intercept of the straight line. The equilibrium constant is correlated to the standard free energy of adsorption, $\Delta G_{a d s}^{0}$ by the following Equation (6):

$$
\Delta G_{a d s}^{0}=-R T \operatorname{In}\left(55.5 K_{a d s}\right)
$$

$R$ is the universal gas constant, $T$ is the absolute temperature and value 55.5 is given as the concentration of water in the solution [31]. The measured data are presented in Table 4. 


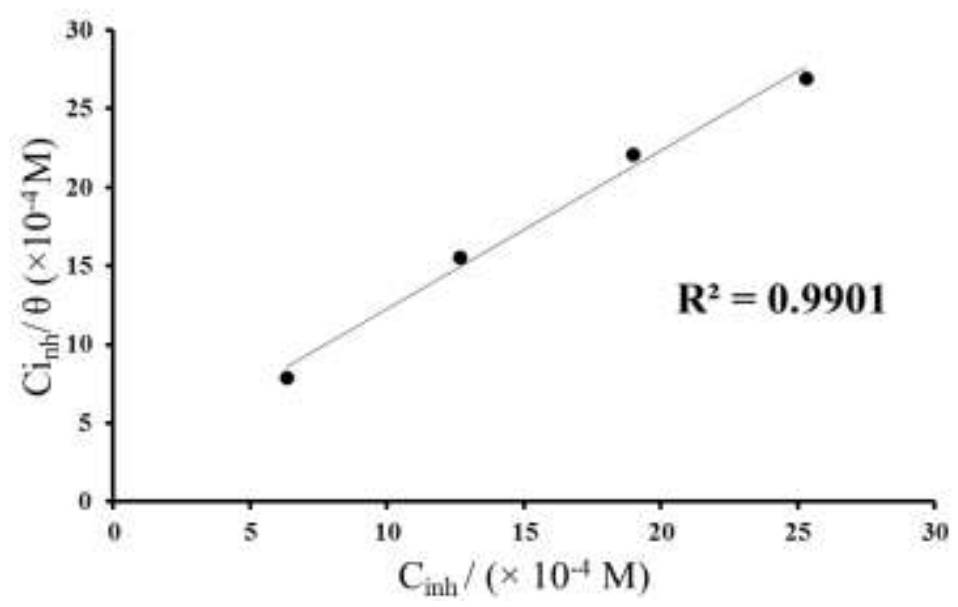

Figure 7. Langmuir adsorption isotherm for carbon steel in the presence and absence of various concentrations of [BMIM][MOPS] at $25^{\circ} \mathrm{C}$

Table-4. Adsorption parameter for carbon steel in the presence and absence of various concentrations of [BMIM] [MOPS] at $25^{\circ} \mathrm{C}$.

\begin{tabular}{ccc}
\hline Compound & $\begin{array}{c}K_{a d s} \\
\left(\mathrm{M}^{-1}\right)\end{array}$ & $\begin{array}{c}-\Delta G_{a d s}^{0} \\
\left(\mathrm{~kJ} \mathrm{~mol}^{-1}\right)\end{array}$ \\
\hline$[\mathrm{BMIM}][\mathrm{MOPS}]$ & 538.06 & 25.53 \\
\hline
\end{tabular}

The negative value of $\Delta G_{a d s}^{0}$ as calculated from Equation (6) indicates a spontaneous adsorption of the inhibitor on the steel surface and reflects a strong interaction of the inhibitor molecules and metal surface [32]. It was established that when the $\Delta G_{a d s}^{0}$ values is around $20 \mathrm{~kJ} \mathrm{~mol}^{-1}$ or lower, a process of physical adsorption may occur through electrostatic interactions between charged inhibitor and metal surface. A chemical adsorption takes place when the $\Delta G_{a d s}^{0}$ values are around $-40 \mathrm{~kJ} \mathrm{~mol}^{-1}$ or higher [33]. In this study, the calculated value of $\Delta G_{a d s}^{0}$ is less than $-40 \mathrm{~kJ} \mathrm{~mol}^{-1}$, which probably suggest the physisorption exist in the interaction of the CI and metal surface [34]. As observed by the chemical structure of [BMIM][MOPS] in Figure 1, the presence of lone pairs on the anion structure of buffer (Oxygen and Sulphur), significantly enhances the electron density [35] around the nitrogen groups, resulting in increased inhibition efficiency. The protonated imidazolium cation enhances the adsorption process thus providing a better protection barrier [36].

\section{Surface Study by Scanning Electron Microscopy (SEM)}

Figure 8a represents the surface of X52 carbon steel after 8 hours of immersion in $1 \mathrm{M} \mathrm{HCl}$ in the absence of inhibitor molecule. Strongly damaged surface roughness is noticed on the metal surface probably due to $\mathrm{Cl}^{-}$ion attack in the absence of ionic liquid [37]. Figure 8b, by comparison represents the surface of carbon steel immersed in $1 \mathrm{M} \mathrm{HCl}$ in the presence of $800 \mathrm{ppm}$ of [BMIM][MOPS] with constant immersion period. Significantly reduced surface 
cavities were observed on the steel surface, suggesting the formation of protective film on the steel surface which was responsible for the inhibition of carbon steel corrosion. [38].
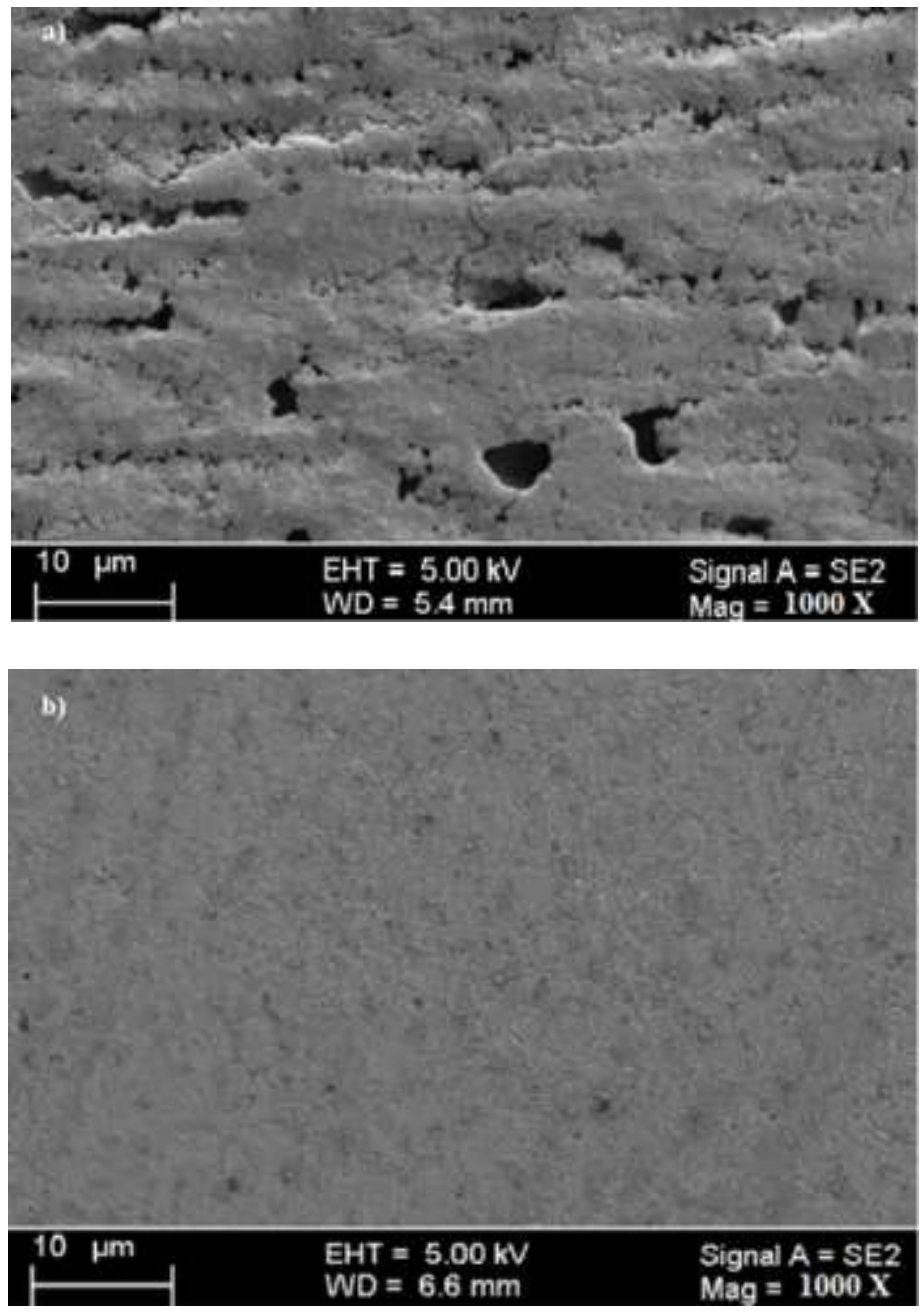

Figure 8. SEM images of X52 carbon steel (a) after 8 hours of immersion in $1 \mathrm{M} \mathrm{HCl}$ solution in the absence (b) and presence of $800 \mathrm{ppm}$ of [BMIM][MOPS] at $25^{\circ} \mathrm{C}$

\section{CONCLUSIONS}

In this work, the inhibition performance of the synthesized ionic liquids on carbon steel corrosion in $1 \mathrm{M} \mathrm{HCl}$ at temperature $25^{\circ} \mathrm{C}$ was measured utilizing weight loss and electrochemical methods. The outcome demonstrated that the synthesized ionic liquids capable in reducing the corrosion rate of the carbon steel in $1 \mathrm{M} \mathrm{HCl}$. Optimal inhibition performance of [BMIM][MOPS] at $800 \mathrm{ppm}$ could reach up to $90 \%$. The ionic liquid hindered corrosion by adsorbing themselves on the surface of the carbon steel. The studied IL act as a mixed type inhibitor in $1 \mathrm{M} \mathrm{HCl}$ solution through the Tafel polarization analysis. The efficiencies of inhibition intensify with increasing concentration at a constant temperature. The adsorption process of the corrosion inhibitor on the carbon steel surface 
was spontaneous and obeyed Langmuir adsorption isotherm. Scanning electron microscopy images demonstrated a smooth and enhanced surface condition with increasing concentration of [BMIM][MOPS] in $1 \mathrm{M} \mathrm{HCl}$ medium. It indicates that the synthesized ionic liquid showed high inhibition performance and potentially be used as a carbon steel corrosion inhibitor in acidic medium.

\section{ACKNOWLEDGMENTS}

This project is funded by Yayasan Universiti Teknologi PETRONAS through Fundamental Research Grant Scheme (YUTP-FRG/2016/0153AA-E31). Nanthini Raman would like to acknowledge UTP for the Graduate Assistance Scheme.

\section{REFERENCES}

[1] Mobin M, Zehra S, Aslam R. RSC Advances PAPER a green corrosion inhibitor for mild steel in hydrochloric acid solution and the effect of surfactant additive. Royal Science Chemistry Advance 2016;6:5890-5902.

[2] Gonfa G, Bustam MA, Man Z, Mutalib AMI. Unique Structure and Solute-Solvent Interaction in Imidazolium based Ionic Liquids. Research Journal of Chemistry and Environment 2012;16:93-103.

[3] Zhang QB, Hua YX. Corrosion inhibition of mild steel by alkylimidazolium ionic liquids in hydrochloric acid. Electrochima Acta 2009;54:1881-1887.

[4] Olivares-Xometl O, Likhanova NV, Domínguez-Aguilar MA, Hallen JM, Zamudio LS, Arce E. Surface analysis of inhibitor films formed by imidazolines and amides on mild steel in an acidic environment. Applied Surface Science 2009;252:2139_ 2152.

[5] Hajipour AR, Rafiee F. Recent Progress in Ionic Liquids and their Applications in Organic Synthesis. OrganicPreparation and Procedures International 2015; 47:1-60.

[6] Yousefi A, Javadian S, Dalir N, Kakemam J, Akbari J. Imidazolium-based ionic liquids as modulators of corrosion inhibition of SDS on mild steel in hydrochloric acid solutions: experimental and theoretical studies. Royal Society of Chemistry Advances 2015;16:11697-11713.

[7] Likhanova NV, Domínguez-Aguilar MA, Olivares-Xometl O, Nava-Entzana N, Arce $\mathrm{E}$, Dorantes $\mathrm{H}$. The effect of ionic liquids with imidazolium and pyridinium cations on the corrosion inhibition of mild steel in acidic environment. Corrosion Science 2010;52:2088-2097.

[8] Armand M, Endres F, MacFarlane DR, Ohno H, Scrosati B. Ionic-liquid materials for the electrochemical challenges of the future. Nature Materials 2009; 8:621-629.

[9] Olivares-Xometl O. Adsorption and corrosion inhibition performance by three new ionic liquids on API 5L X52 steel surface in acid media. Industrial and Engineering Chemistry Research 2014;53:9534-9543.

[10] Cruz J, Martínez R, Genesca J, García-Ochoa E. Experimental and theoretical study of 1-(2-ethylamino)-2-methylimidazoline as an inhibitor of carbon steel corrosion in acid media. Journal of Electroanalytical Chemistry 2004;56:111-121. 
[11] Olivares-Xometl O, Likhanova NV, Domínguez-Aguilar MA, Hallen JM, Zamudio LS, Arce E. Surface analysis of inhibitor films formed by imidazolines and amides on mild steel in an acidic environment. Applied Surface Science 2009; 252: 2139_ 2152.

[12] Thiel T, Liczkowski L, Bissen ST. New zwitterionic butanesulfonic acids that extend the alkaline range of four families of good buffers: Evaluation for use in biological systems. Journal of Biochemical and Biophysical Methods 2001;37:117-129.

[13] Taha M, Silva FA, Quental MV, Ventura SPM, Freire MG, Coutinho JAP. Good's buffers as a basis for developing self-buffering and biocompatible ionic liquids for biological research. Green Chemistry 2014;16:3149-3159.

[14] Nady H. Tricine [ N- ( Tri ( hydroxymethyl ) methyl ) glycine ] - A novel green inhibitor for the corrosion inhibition of zinc in neutral aerated sodium chloride solution. Egyptian. Journal of Petrochemical 2016;17:231-238.

[15] Abdel Rahim MA, Hassan HB, Khalil MW. Naturally occurring organic substances as corrosion inhibitors for mild steel in acid medium. Materialwissenschaft Werkstofftechnik 1997;28:98-102.

[16] Nalini D, Rajalakshmi R, Subhashini S. Corrosion Inhibition of Mild Steel in Acid Solution by 3,4,5-Trimethoxyphenyl-2-imidazolines. E-Journal of Chemistry 2013; 8: 671-679.

[17] Zhang Q, Hua Y. Corrosion inhibition of aluminum in hydrochloric acid solution by alkylimidazolium ionic liquids. Materials Chemistry and Physics 2010;119: 57-64.

[18] Atta AM, El-Mahdy GA, Al-Lohedan HA, Ezzat AR. A new green ionic liquid-based corrosion inhibitor for steel in acidic environments. Molecules 2015; 20:1113111153.

[19] Hooshmand Zaferani S, Sharifi M, Zaarei D, Shishesaz MR. Application of ecofriendly products as corrosion inhibitors for metals in acid pickling processes - A review. Journal of Environmental Chemical Engineering 2013;1:652-657.

[20] Verma C, Ebenso EE, Quraishi MA. Ionic liquids as green and sustainable corrosion inhibitors for metals and alloys: An overview. Journal of Molecular Liquid 2017; 233:403-414.

[21] Mourya P, Banerjee S, Singh MM. Corrosion inhibition of mild steel in acidic solution by Tagetes erecta (Marigold flower) extract as a green inhibitor. Corrosion Science 2014; 85:352-363.

[22] Deyab MA, Zaky MT, Nessim MI, Inhibition of acid corrosion of carbon steel using four imidazolium tetrafluoroborates ionic liquids. Journal of Molecular Liquid 2017;229:396-404.

[23] Bastidas JM, Polo JL, Cano E. Substitutional inhibition mechanism of mild steel hydrochloric acid corrosion by hexylamine and dodecylamine. Journal of Applied Electrochemistry 2001;30,1173.

[24] Solmaz R, Kardaş G, Çulha M, Yazici B, Erbil M. Investigation of adsorption and inhibitive effect of 2-mercaptothiazoline on corrosion of mild steel in hydrochloric acid media. Electrochima Acta 2008;53:5941-5952.

[25] Matad PB, Mokshanatha B, Hebbar N, Venkatesha VT, Tandon HC, Ketosulfone drug as a green corrosion inhibitor for mild steel in acidic medium. Industrial and Engineering Chemistry Research 2014; 53:8436-8444.

[26] Yadav M, Yadav PN, Sharma U. Substituted imidazoles as corrosion inhibitors for 
N80 steel in hydrochloric acid. Indian Journal of Chemical Technology 2013; 20:363-370.

[27] Al-Amiery AA, Kadhum AAH, Alobaidy AHM, Mohamad AB, Hoon PS. Novel corrosion inhibitor for mild steel in HCl. Materials 2014;7:662-672.

[28] Kermanioryani M. Physicochemical properties of new imidazolium-based ionic liquids containing aromatic group.Journal of Chemical Engineering Data 2016;61:2020-2026.

[29] Gerengi H, Sahin HI. Schinopsis lorentzii extract as a green corrosion inhibitor for low carbon steel in $1 \mathrm{M} \mathrm{HCl}$ solution. Industrial and Engineering Chemistry Research 2012;51:780-787.

[30] Gupta BS, Fang M, Lee M. Application of Buffer-Based Ionic Liquid in the Separation of 1, 4- Dioxane from Its Azeotropic Aqueous Solution. Journal of Florine Chemistry 2018;127:159-176.

[31] Bouanis M, Tourabi M, Nyassi A, Zarrouk A, Jama C, Bentiss F. Corrosion inhibition performance of 2,5-bis(4-dimethylaminophenyl)-1,3,4-oxadiazole for carbon steel in $\mathrm{HCl}$ solution: Gravimetric, electrochemical and XPS studies. Applied. Surface. Science 2016; 389:952-966.

[32] Shukla SK, Murulana, Ebenso EE. Inhibitive effect of imidazolium based aprotic ionic liquids on mild steel corrosion in hydrochloric acid medium. International Journal of Electrochemical Science 2011;6:4286-4295.

[33] Ikpi ME, Abeng FE, Obono OE. Adsorption and Thermodynamic Studies for Corrosion Inhibition of API 5L X-52 Steel in $2 \mathrm{M} \mathrm{HCl} \mathrm{Solution} \mathrm{by} \mathrm{Moxifloxacin.}$ Journal of National Science 2017; 9:52-61.

[34] Kadhum AAH, Mohamad AB, Hammed LA, Al-Amiery AA, San NH, Musa AY. Inhibition of mild steel corrosion in hydrochloric acid solution by new coumarin. Materials 2014; 7, 4335-4348.

[35] Ullah S, Bustam MA, Shariff AM, Gonfa G, Izzat K. Experimental and quantum study of corrosion of A36 mild steel towards 1-butyl-3-methylimidazolium tetrachloroferrate ionic liquid. Applied Surface Science 2016; 365:76-83.

[36] He X, Jiang Y, Li C, Wang W, Hou B, Wu L. Inhibition properties and adsorption behavior of imidazole and 2-phenyl-2-imidazoline on AA5052 in 1.0M HCl solution. Corrosion Science 2014;83:124-136.

[37] Mendes JO, Da Silva EC, Rocha AB. On the nature of inhibition performance of imidazole on iron surface. Corrosion Science 2012; 57:254-259.

[38] Gabler C, Tomastik C, Brenner J, Pisarova L, Doerr N, Allmaier G. Corrosion properties of ammonium based ionic liquids evaluated by SEM-EDX, XPS and ICPOES. Green Chemistry 2011;13: 2869. 